\title{
The Aponeurotic Tension Model of Craniofacial Growth in Man
}

\author{
Richard G. Standerwick ${ }^{1, *}$ and W. Eugene Roberts ${ }^{2}$ \\ ${ }^{1} 20159$ - 88th Ave, Suite E207, Langley BC V1M 0A4, Canada and ${ }^{2} 5955$ S. Emerson Avenue, Ste. 200, Indianapolis, IN \\ 46237, USA
}

\begin{abstract}
Craniofacial growth is a scientific crossroad for the fundamental mechanisms of musculoskeletal physiology. Better understanding of growth and development will provide new insights into repair, regeneration and adaptation to applied loads. Traditional craniofacial growth concepts are insufficient to explain the dynamics of airway/vocal tract development, cranial rotation, basicranial flexion and the role of the cranial base in expression of facial proportions. A testable hypothesis is needed to explore the physiological pressure propelling midface growth and the role of neural factors in expression of musculoskeletal adaptation after the cessation of anterior cranial base growth.

A novel model for craniofacial growth is proposed for: 1. brain growth and craniofacial adaptation up to the age of 20; 2 . explaining growth force vectors; 3 . defining the role of muscle plasticity as a conduit for craniofacial growth forces; and 4. describing the effect of cranial rotation in the expression of facial form.

Growth of the viscerocranium is believed to be influenced by the superficial musculoaponeurotic systems (SMAS) of the head through residual tension in the occipitofrontalis muscle as a result of cephalad brain growth and cranial rotation. The coordinated effects of the regional SMAS develop a craniofacial musculoaponeurotic system (CFMAS), which is believed to affect maxillary and mandibular development.
\end{abstract}

Key Words: Brain, Aponeurotic, Airway, Mandible, Rotation, Muscle, SMAS.

\section{INTRODUCTION}

The soft tissue matrix, in which skeletal elements are embedded, is the primary determinant of growth, while both the bone and cartilage are secondary growth sites. Growth centers display inherent growth versus growth sites which are reactive $[1,2]$.

This is the fundamental premise of the Functional Matrix Theory of Melvin Moss [3]. The soft tissue matrix (muscles, connective tissue, neural tissue) models the bone, rather than bone morphology being genetically determined.

Proposed is a descriptive model of craniofacial growth based on the principle that late brain growth and cranial rotation create a residual tension in the occipitofrontalis muscles which in turn loads the facial superficial musculoaponeurotic systems (SMAS) via connected fascia, muscle and ligaments and reflect a craniofacial musculoaponeurotic system (CFMAS).

\section{PURPOSE}

The purpose of this review is to provide a comparative, biologically accurate and clinically effective framework for understanding [4] the coordination of brain and craniofacial growth (CFG), and the relationship of brain growth to cranial rotation, airway and vocal development. There is a strong belief that the musculoaponeurotic system of the skull has a direct effect on maxillary and mandibular development, and

\footnotetext{
*Address correspondence to this author at the 20159 - 88th Ave, Suite E207, Langley BC V1M 0A4, Canada; Tel: (604) 888-3450;

E-mail: rjstanderwick@gmail.com
}

forms the underlying theme of the proposed aponeurotic tension model of craniofacial growth.

\section{TRADITIONAL CONCEPTS}

Moss introduced the functional matrix theory describing skeletal growth as a secondary, compensatory, and mechanically obligatory response to temporally and morphogenetically prior growth changes in specially related tissues and organs [5-7]. A solitary growth matrix for the entire head is difficult to explain, therefore Moss divided the head into areas (capsular matrices) such as the neurocranial capsular matrix and the orofacial capsular matrix [8], the latter being comprised of the teeth, sinus spaces, muscles and connective tissue (blood vessels, etc...). Neurocranial capsular matrix enlargement resulting from neural growth seems selfevident. However, the nature of the orofacial capsular matrix growth is more elusive. It is believed that the orofacial capsular matrix enlargement is driven by airway enlargement and that the direction of this facial growth is caudad and ventral (Fig. 1).

The nasal septum model of Scott [9] describes the nasal septum as a growth center forcing the viscerocranium caudad and ventral relative to the cranial base until the facial sutures have become stabilized by dense connective tissue $[9,10]$. The nasal septum directs prenatal and some postnatal growth to the approximate age of 4 years, [4] but the brain is believed to be the primary growth center for CFG until approximately the age of 8 [11]. After neural growth is complete, the more inferior portions of the anterior cranial base (ACB) are considered to continue "growing" caudad and 

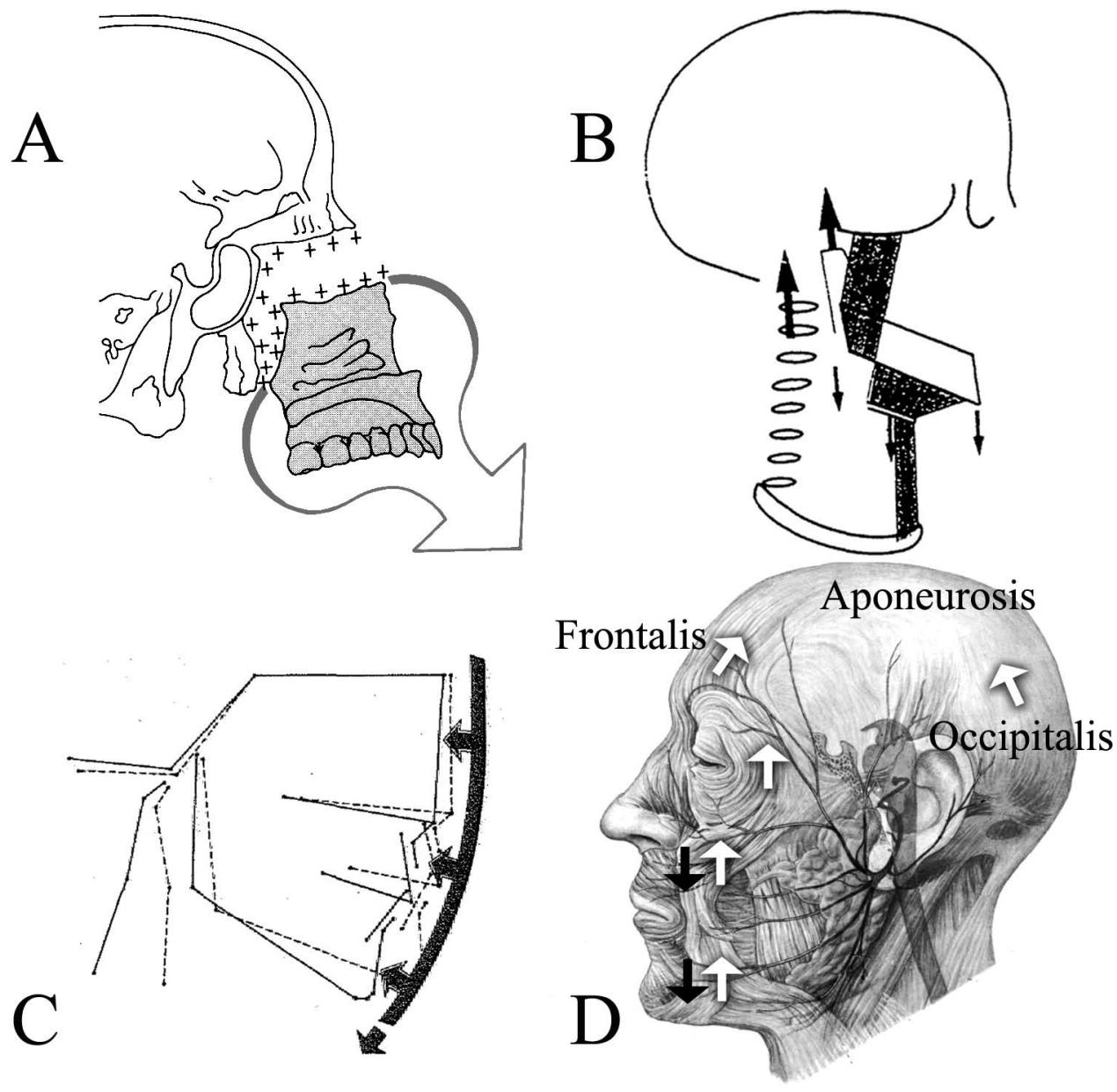

Fig. (1). (A) Displayed is the ventral and caudad growth direction of the ethmomaxillary complex Illustration from [1]. (B) Houston [16] combined his CFG model based on cervical vertebrae growth, with (C) the soft-tissue stretching of Solow [17] and cranial posture changes [114]. Illustrations from [16, 17]. Houston's model cannot explain forward/counter-clockwise mandibular rotation. (D) An anatomical drawing of the aponeurotic tension model of craniofacial growth. Shown are: the force of gravity (black arrows) and CFMAS tension (white arrows); the frontalis muscle (frontalis), the occipitalis muscle (occipitalis) and the area between is the location of the galea aponeurotica (aponeurosis). The modiolus (muscular confluence joining the upper portion of the muscle mask with the lower portion) is found vertically between the black arrows overlying the cheek and chin. Illustration adapted from [115].

ventral, causing drift and displacement of the ethmomaxillary (midface) complex [11-13] in conjunction with growth at the sphenooccipital synchondrosis (SOS: a hyaline cartilage growth center between the clivus of the occipital bone and sphenoid bone) [13]. The anteroposterior force of the SOS displacement is believed by some to be transmitted through the nasal septum acting as a strut connecting to the midface $[4,13,14]$. Alternatively, the advancement of the midface could be a result of physical growth forces of enclosing soft tissues. For example, displacement of facial sutures could result from the enlargement of muscles, [13] or from growth of the brain temporal lobe, infraorbital and retromaxillary fat pads, and infratemporal fossa contents (pterygoid muscles, fat pads) creating a laterally transmitted force to the midface $[11,15]$.

The facial tissues have previously been described by Houston [16] and Solow [17] (Fig. 1), as influencing facial growth but from the aspect of growth restriction and postural change through soft tissue forces by facial application of a dorsally directed force to the underlying skeletal structures. The Servosystem model of Petrovic [18] assumes the dis- placement of the midface through nasal septum growth in conjunction with direct thrust of labionarinary muscles, and through the superior labial frenum and septopremaxillary ligament [19]. As the maxilla is moved ventrally there is believed to be compensation maintaining the mandibular relationship to the maxilla.

Although each of the models has added to our attempt at understanding CFG, none of the CFG models seem to directly neither address nor provide a model for the differing patterns of maxillomandibular rotation in hypo- and hyperdivergent individuals as described by Bjork [20,21]. There are inconsistencies found in earlier theories that are believed more effectively addressed with the proposed CFG model. The proposed model explains why the airway enlarges sagittally, despite a backward slide of the vomer between infancy and adulthood [11]. If it were the only issue, the relative descent of the larynx would be plausible with traditional caudad and ventral CFG model as there is significant growth of the cervical vertebrae, for which the heights of the vertebrae roughly double by growth at their respective epiphyseal plates [22]. However, Houston's cervical growth 
model [16] cannot explain forward mandibular rotation as the tissue are oriented to provide a dorso-caudad force.

Also, the maxilla is believed to display "growth" at the maxillary tuberosity causing pressure against the pterygoid plate of the sphenoid bone. This pressure is believed to displace the maxilla forward. However, between the pterygoid plate and maxilla there is a fibrous suture rather than synchondrosis. Compression in sutures has been shown to display resorption [23-25] and the bone (pterygoid plates) in the area is much too pliable in that environment to withstand the pressures [26]. The lack of inherent growth potential of sutures negates any ventral thrust of midface growth by the circumaxillary suture system $[2,4,14]$. The viscerocranial units (maxilla, mandible) seem suspended in CFMAS relative to cranial rotation concomitant with allometric brain growth. Further investigation of the degree of viscerocranial suspension by the CFMAS relative to elastic fiber and collagen fiber resistance within the suture itself seems warranted.

The relative fixed position of the zygomatic processes as the remainder of the maxilla is thrust forward is assumed to be a result of maxillary resorption anteriorly and deposition posteriorly [26]. Problematic is that the anterior resorption is superficial as the anterior surface displays stability relative to endosseous implants. Essentially, all of the increase in maxillary length occurs posteriorly [27-29]. Considering the limitations of microscopic histology, this process requires further study with intravital markers [30]. Cranial rotation better explains the observed pattern of surface resorption anteriorly due to pressure applied by CFMAS weight to the anterior region during the rotation. Surface resorption is created as bone advances into the drape of the CFMAS pressure which is created on the anterior bone leading to collapse of the vasculature, stimulating compensatory modeling. Deposition posteriorly is stimulated by tension created within the suture by cranial rotation and the associated force of the CFMAS. Cranial rotation and the facial block concept [12, 31] would rectify the conflict of Bjork's observations displaying a stable zygomatic surface relative to implants [27], while Enlow believed the zygoma relocated dorsally [13]. Both were correct. The rotation of the maxilla relative to the zygoma would display a stable zygoma surface relative to an implant, while slight surface resorption of the zygoma would be observed due to pressure of the facial muscle mask. The rotation of the maxilla would be displaced forward relative to the zygoma leading to the conclusion that the zygoma must be posteriorly displaced with growth. This also explains the observation that the mandible growth rotation is greater that maxillary growth rotation; at the same time, the mandible is also rotating around the maxilla [32].

\section{ALTERNATIVE MODEL INTRODUCED TO SUP- PLEMENT THE CURRENT UNDERSTANDING OF CRANIOFACIAL GROWTH IN MAN}

Proposed is an alternative model of CFG based on musculoaponeurotic tension enveloping the head. This CFG model describes the affect of late cephalad growth of the brain pushing on the occipitofrontalis muscle (Figs. 1 and 2), which places the muscles in tension, the peak in temporal and occipital lobe gray matter being at 16-20 of years age [33]. The tension force is transmitted from the occipitofrontalis muscles down through the mask of muscles overlying the face due to individual muscle fiber blending with adjacent muscles and the associated superficial musculoaponeurotic systems (SMAS; investing connective tissues) [34-40]. This facial muscle mask and associated regional SMAS are believed to be part of a CFMAS important in directing craniofacial development and jaw rotation by acting as a conduit for the brain derived force. Cranial rotation [12, 41] is also believed to occur sagittally around the atlantooccipital joint as a result of allometric brain growth and progressive facial bone pneumatization with sinus development.

Brain extension consists of uprighting of the cerebral portion of the brain, and therefore also the head, relative to the body axis during growth and development. This pattern is mimicked by cranial base (basicranial) flexure [12, 41] and airorhynchy (posterior and upper portions of the face rotate dorsally relative to the posterior cranial base by extension of the ACB relative to the posterior cranial base (PCB), analogous with the "facial block") [12] (Fig. 3). Cranial rotation being intimately integrated with the latter, the term cranial rotation will be used collectively for them from this point. It is possible that the proposed model applies to only humans as it seems coordinated with cranial base flexion during growth which is unique to humans [12].

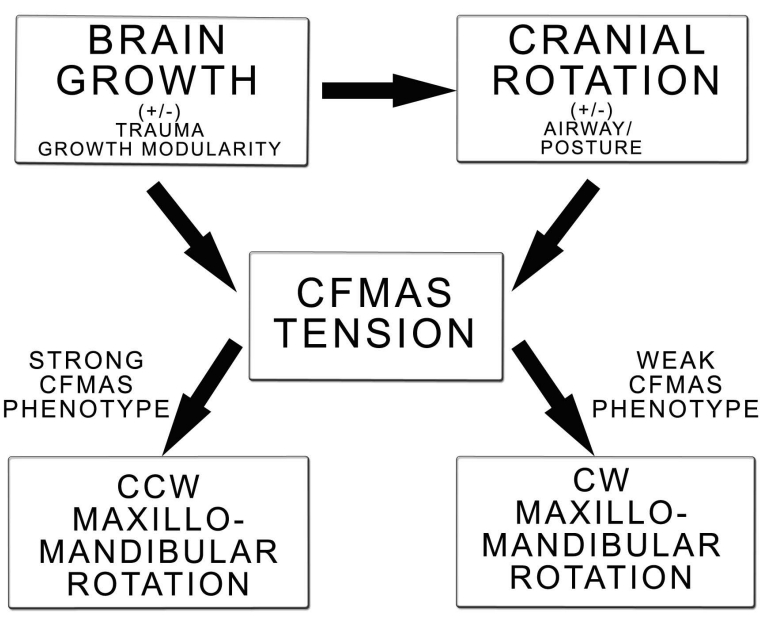

Fig. (2). Algorithmic adaptation of the proposed CFG model. Displayed is brain growth modulation of cranial rotation and CFMAS tension. Brain growth can display temporal regional growth and mylenization with normal development and as a result of trauma (concussion, drug use). Cranial rotation modulates CFMAS tension and itself is influenced by brain development and postural control. CFMAS tension manifests as as a strong or weak phenotype. A strong CFMAS phenotype will be expected to develop a counterclockwise/forward maxillomandibular rotation, while a weak CFMAS phenotype will be expected to develop a clockwise/ backward maxillomandibular rotation pattern.

\section{Brain Growth and Craniofacial Adaptation up to the Age of 20}

Lateral cranial expansion is limited after approximately 1 year of age $[10,14]$ and ACB anteroposterior growth is limited by 8 years of age with the fusion of sphenoethmoid, frontoethmoid and intersphenoid synchondroses [11]. The 

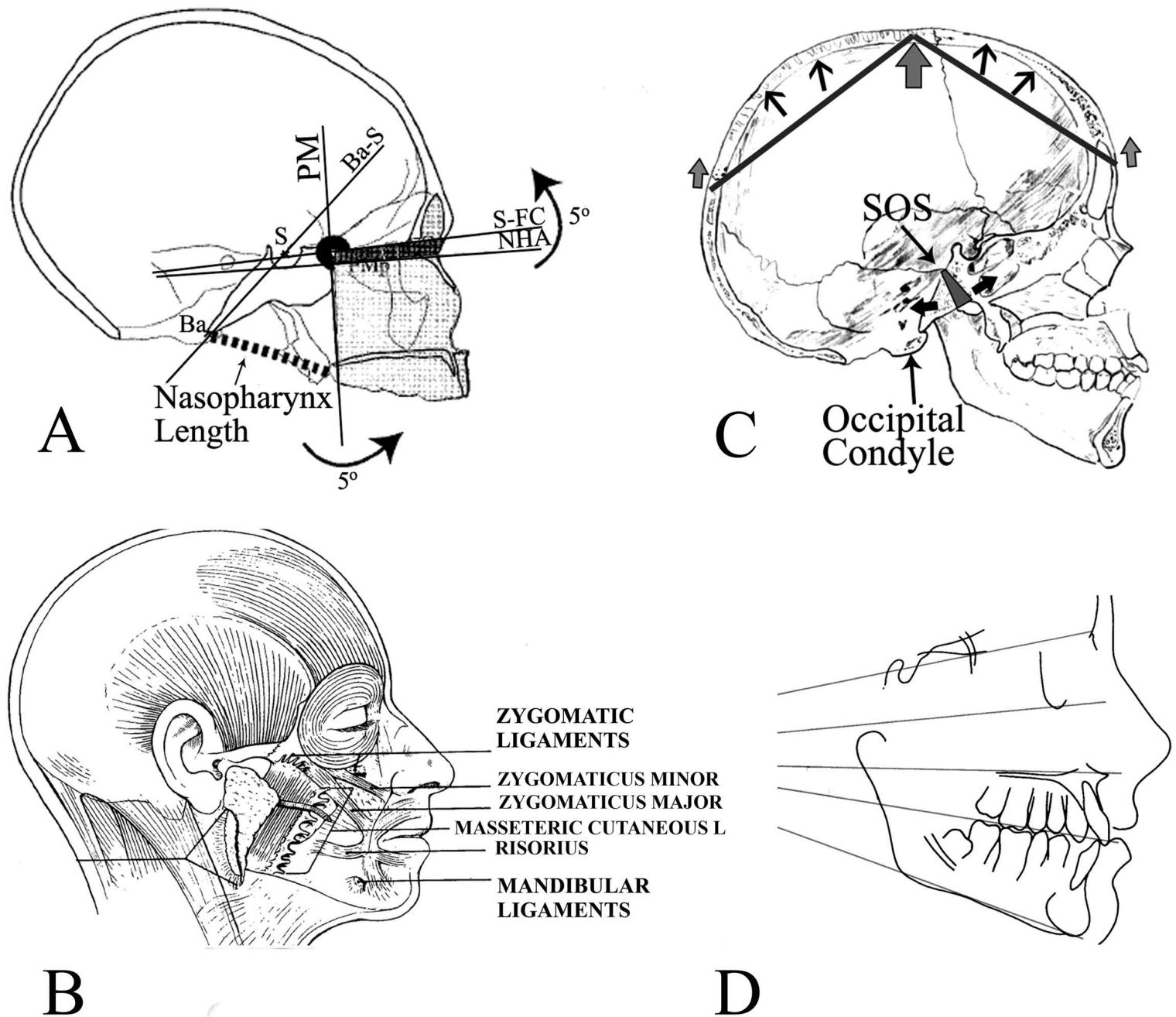

$\mathrm{D}$

Fig. (3). (A) The "facial block" showing the effects of angular invariance between the back of the face (summarized by the PM plane) and the top of the face, which is also the bottom of the anterior cranial base (S-FC). Changes in cranial base angle (NHA-BaS or alternatively $\mathrm{S}-\mathrm{FC}-\mathrm{BaS}$ ) cause the top and back of the face to rotate together around an imaginary axis through the PM point [12]. Illustration from [12]. (B) Osteocutaneous ligaments that originate from periosteum and insert directly into dermis (zygomatic and mandibular ligaments are shown; zygomaticus minor and major muscles, masseteric cutaneous ligaments and risorius are also shown). Note the modiolus as a confluence of muscles located at the angle of the mouth. Illustration from [54]. (C) Skull in norma lateralis shows the asymmetric growth of the spheno-occipital synchondrosis. Tension on the aponeurosis (arrows at glabella and occipital nuchal line) are expressed as an inverted $\mathrm{V}$ with the net force at the center of the skull, superior to the occipital condyle (large arrow). This is expected to create a lever system (dark lines) pivoting at the large arrow and extending to the smaller arrows. These are the effective forces of the muscles on the dorsal and ventral skull surface. (D) The divergence of the facial planes (sella-nasion at the top and then descending; orbitale-porion or the Frankfort horizontal; palatal plane; occlusal plane; mandibular plane).

brain temporal lobe continues growing for several more years after brain anterior lobe growth has ceased [13]. However, elongation of the middle cranial fossa (MCB) nearly ceases by 10 years of age [11]. Therefore, it is proposed that most brain growth must be in a cephalad direction [12].

The concept of a cephalad growth component is derived from the works of Bergersen [42], Bjork [21, 32, 41], Broadbent [43], Coben [44], Kanomi (K point), Melsen [45] and current observations superimposing overlay tracings of sequential cephalometric radiographs referenced on the occipital condyles [46, 47]. All of these data demonstrate cephalad movement of sella turcica relative to the PCB of the skull [46, 47]. Microscopic evidence of cephalad brain movement is evident as bone apposition along the surfaces of sella turcica, including the anterior curvature of sella turcica, which is traditionally considered stable yet displays pubertal apposition [10, 13, 45, 48, 49]. Late brain growth beyond what is traditionally accepted is consistent with more recent observations. For example, brain allometry has been observed with peak development of gray matter at approximately the age of 12 for the frontal and parietal lobes, age 16 for the temporal lobes, and through 20 for the occipital lobe [33]. Moreover, gender related pubertal spurts in brain growth suggest gonadal hormone influence, [33] and coincide with the somatic growth spurt. 
This late brain growth may not have been previously apparent as traditional methods of intercranial volume measurement could be misleading. Radiographic midline structures may not be an adequate reference, [50] anthropometric measurements may not be reliable, [51] and the stability of the ACB structural midline at age 10 is only valid for the ethmoid region [41].

Traditionally, weight of the growing brain is expected to cause surface resorption on the endocranial aspect of the human cranial base, $[13,48]$ but this has not been experimentally tested [12]. Intravital staining and an accurate specimen age are still needed to establish the quantity and temporal nature of deposition or resorption for the endocranial compartments with growth and development [30] as assessment of these is impossible with microscopic histology.
Cranial base flexion during growth is unique to humans and complements inferior drift in the PCB by moving the floor of the PCB caudad relative to the middle cranial fossa [12]. The surface resorption of the cranial fossa seems negligible when comparing the growth of the PCB relative to the position of the occipital condyles, MCB and ACB [46, 47, 52]. The occipital condyles are a stable structure to reference due to the lack of an epiphyseal growth plate in the presence of a large pressure gradient $[2,46,47]$. The observed movement with the occipital condyle reference seems to correlate with the observation that PCB displays relative inferior drift which positions the PCB below the middle cranial fossa [12]. Growth of the basilar region of the skull must be limited to avoid impinging on critical neural structures [12] and therefore dural "slings" cradle the brain and restrict growth that might compromise neurologic function (Fig. 4). The des-

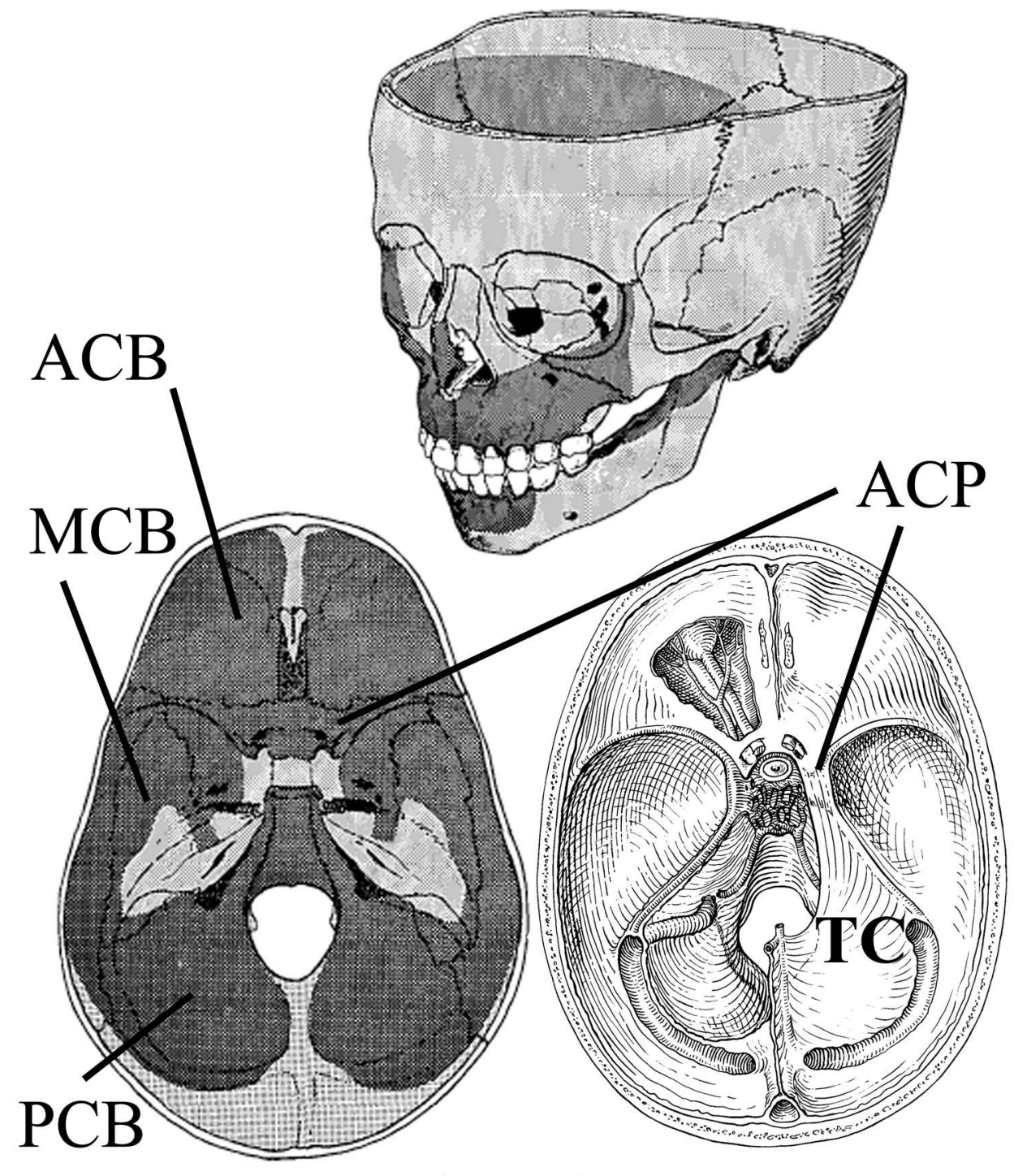

Fig. (4). Cranial resorption (dark stipple) and deposition patterns (light stipple) are illustrated on sectioned skulls. Areas of bone deposition are along the petrous portion of the temporal bone, crista galli/foramen cecum, between the occipital lobes, and sella turcica. The anterior (ACB), middle (MCB) and posterior (PCB) cranial fossa are shown (bottom left). The proposed normal distribution of facial bone resorption and deposition is shown (top). Bottom right displays the desmocranial lining of the cranial base; the lining is continuous with the falx cerebri but shown are the tentorium cerebelli (TC) and its attachment to the anterior clinoid process (ACP). This connection spans the SOS creating tension on the endocranial aspect of the SOS and contributing to differential growth of the SOS. Illustration from [48]. 
mocranial capsule (dura) is anisotropic, being thicker at its base which grows slowly and resists the enlargement of the brain in the developing cranial base. Over the calvarial region it is thinner and less resistant, allowing the cerebral hemispheres, and to a lesser extent, the cerebellar hemispheres to expand more rapidly [10, 53]. Also, cephalad brain growth better explains why the entire cranial base surface is not resorptive, but displays areas of bone deposition: the petrous portion of the temporal bone, crista galli/foramen cecum, between the occipital lobes, and sella turcica [13, 48] (Fig. 4). Continued relative growth of the PCB into the adolescent years is an important factor that has not been adequately appreciated. The relative effects of cephalad brain growth warrant further study.

\section{Explaining Growth Force Vectors}

Mitz and Peyronie (Mitz and Peyronie, 1976) originally coined the term SMAS, yet despite numerous publications on this subject, there remain significant variations in the anatomic descriptions of facial fascial anatomy, and descriptions of the relationship between the superficial and deep facial fascia remain imprecise [54]. The SMAS is a composite fibro-fatty layer comprising collagen and elastic fibers interspersed with fat cells. It microscopically displays a considerable amount of elastic fibers in close relationship to the collagen fibers, and the collagen fibers display a convoluted appearance similar to that found in the dermis [55]. The SMAS invests the superficially lying mimetic muscles (muscles of facial expression; e.g. platysma, orbicularis oculi, zygomaticus major, and risorius) and forms a continuous sheath throughout the head and neck, extending into the temporal region, forehead, scalp, malar areas, nose and upper lip. Thus the superficial facial fascia is intimately associated with the mimetic muscles $[54,56]$. The mimetic muscles and SMAS function as a single anatomic unit in producing movement of facial skin [54] and the low viscoelastic properties of the SMAS are the reason for incorporation of the SMAS as a standard part of the rhytidectomy (facial lift) procedure [55, 57]. Also deserving further investigation and consideration are the relatively thick osteocutaneous retaining ligaments that anchor periosteum to dermis, notable being the zygomatic and mandibular ligaments [54] (Fig. 3).

The coordinated effect of facial muscle and regional SMAS blending develops a CFMAS. The proposed model provides a more biologically correct explanation for observations that earlier models have been unable to provide satisfactorily. The tension conducted through the CFMAS explains the enlargement of airway and maxillomandibular rotation patterns consistent with the observations of implant studies [28, 58] and cephalometric superimposition referenced at I-point on the occipital condyles in norma lateralis $[46,47]$.

Growth associated force transmittance through mimetic muscles has previously been described by Delaire [59, 60]. CFMAS tension may also be related to resting muscle tonus, [61] which opposes gravity effects resulting from increase in tissue mass (e.g. muscle, fascia, skin, bone, connective tissue, associated hydration of these structures and any cantilever developed). During normal growth it is postulated that the tension through the CFMAS resists the effects of gravity until CFMAS attenuation with late aging [54]. Hemifacial paralysis, (e.g. Bell's Palsy) conveniently displays effect of muscular atonicity resulting in uncompensated gravitational forces upon tissue mass, which is tissue sag (Fig. 5). CFMAS tension transmittance is amplified with muscular growth and development with puberty, along with densification and increased crosslinking of connective tissue component [62] (Fig. 5). An increase in muscle size and fat deposit deep to the SMAS may also have a tendency to place the overlying associated SMAS in tension which exhibits some similarity to the work of Solow $[17,54,56,63]$.

\section{Defining the Role of Muscle Plasticity as a Conduit for Craniofacial Growth Forces}

The CMFAS is an unstable conduit for force transmittance and its development is age dependant, reactive and inherent (genetic).

The traditional view is that bone reacts to muscle forces but that muscle does not react to bone modeling. However, there is increasing evidence that the muscle response is also adaptive to underlying skeletal development [64]. The effect of gravity with increase in bone and muscle mass may stimulate muscle lengthening. In addition to functional muscle development, genetic properties may determine the number of muscle myofibrils, myofibers and myotubes $[65,66]$ and quality of the supporting connective tissue, thereby displaying individual variation.

During muscle growth, there is an increase in length by addition of sarcomeres at the muscle tendon junction for which the rate of sarcomeres addition may vary temporally depending on the individual muscle [67]. At a certain point, the addition of sarcomeres and associated increase in muscle fiber length with growth ceases. Any further increase in muscle belly length is presumed to be a reorganization of muscle fibers as insertion of myofibers into the tendon are not uniform but instead stagger [67]. However, the muscle continues to increase in girth due to myofibril splitting as a result of oblique forces within the sarcomeres when a critical diameter is reached [68]. Immobilization of limbs in both extended or contracted muscular positions displays a decrease in the number of sarcomeres relative to controls, presumably due to the restriction of function $[67,69]$ because the bone length in immobilized specimens is not significantly different than controls. This is assumed to be a result of increase in tendon length [67]. Immobilization is obviously not physiologic as it overpowers the normal function of the Golgi tendon apparatus and occult muscle tonus, thereby stressing ligaments and tendons beyond the normal viscoelastic limits [70]. Therefore, certain observations from immobilization experiments may not be representative of the normal growth process.

As muscle ages, there is a rapid increase in quantity and quality of muscle associated connective tissue and therefore CFMAS; [62, 71-73] this increase may be a phenomenon throughout the connective tissue in the body. Skeletal muscle growth is believed to be rate limited by connective tissue growth which controls myofiber diameter and length [73-75] increasingly as the intramuscular connective tissue arrangement becomes thicker and increasingly cross-linked with age [62] (Fig. 5). The latter is resistant to lengthening compared to the rather compliant muscle fibers $[71,73]$ and relatively small increases in the muscle collagen content increases 

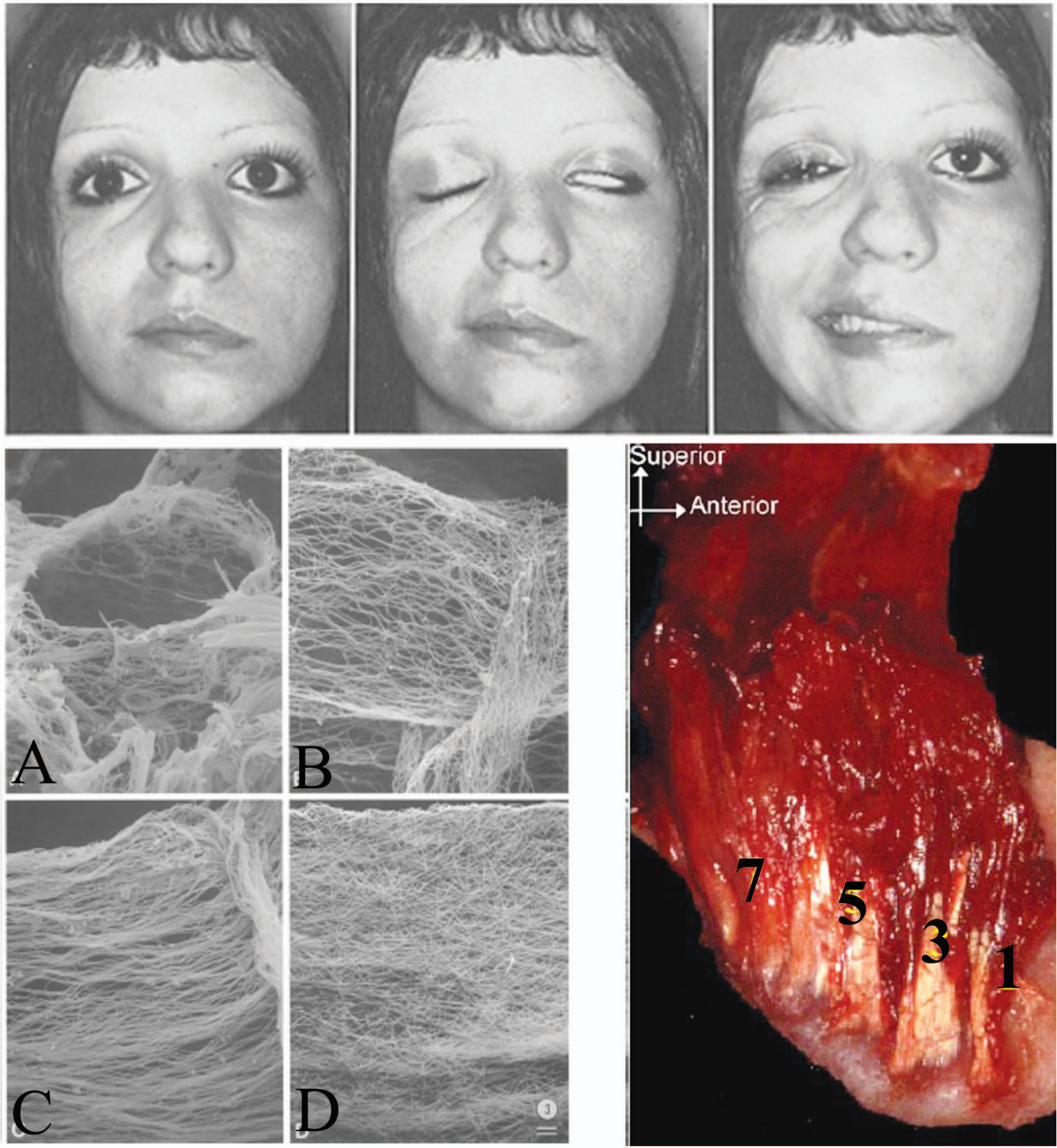

Fig. (5). (Top) Hemifacial paralysis is shown. Notice the tissue sag (left), and the resulting alar contour and relative vertical position between the paralyzed and normal sides (middle). There is arguably a more inferior position of the patient's left orbit and eye. Photograph from [116] (Bottom left) There is a progressive age-related fiber thickening, densification and cross-linking of the connective tissue component of muscles (endomysium, perimysium, and epimysium) (bottom right) [62]. Age dependant directional restriction caused by the process requires further study. Photograph from [62]). (Bottom right) The original pterygomasseteric attachment may be preserved as the ramus grows posteriorly and new muscle attachment heads are developed; numbered from [1] initial/oldest attachment to [7] more recent attachment. Photograph from [103].

muscle rigidity due to the extremely low compliance of collagen $[62,73,76,77]$. A decreased range of motion during distraction osteogenesis of bone (sectioning of a bone, allowing callus formation/primary healing and then applying a force across the wound to stretch the tissues thereby stimulating bone and tissue formation to elongate bones) seems a function of the perimysium adaptation rather than of the muscle fibers $[75,78]$.

As brain growth and cranial rotation decrease with early aging ( $\leq 25-30$ years of age), the influence of CFMAS tension is expected to increase through decreased connective tissue compliance relative to gravity affects on tissue mass 
$[71,73]$ until the age at which brain growth and cranial rotation cease and CFMAS attenuation [54] becomes an issue.

\section{Tension is Transmitted from the Galea Aponeurotica/ Occipitofrontalis to the Cranial Base}

It is postulated that the anteroposterior tension within the occipitofrontalis muscles is the cause of the asymmetric separation of the SOS. The weight of the brain on the desmocranial capsule (dural slings traverse the SOS; Fig. 3) and cranial base, and anteroposterior tension muscle tension within the CFMAS, cause a pivot point at the superior aspect of the SOS creating a greater relative separation of the pharyngeal side of the SOS relative to the endocranial aspect $[45,79]$. A biomechanical lever system would allow smaller increments of brain growth a greater significance in directing facial tension, (Fig. 3) however, a finite element analysis is needed to adequately describe the stresses and distinguish effects.

Asymmetric growth at the SOS has been demonstrated with and without implants as radiologic markers [12, 41, 45, 79-81]. Hyaline cartilage becomes anabolic when induced by tensile stress, which also accelerates endochondral ossification at the pharyngeal surface of the SOS [80, 82-86]. Therefore, it is difficult to demonstrate the asymmetric growth of the SOS radiographically because of concomitant bone modeling. Consideration must be given to the SOS as a reactive site of growth rather than a primary growth center during the adolescent and early adult years [87]. Premature fusion of a cranial suture, craniosynostosis, causes flattening of the basicranium, [88] while inhibition of SOS growth creates a more flexed cranial base [12].

Implants demonstrate that growth of the face does not follow straight lines, but rather curves in association with sutural plane rotation [58]. Rotation of the cranium [12] seems related to allometric brain development [12, 33, 89] and possibly the progression of brain myelination patterns (the water content of fat being less than grey matter), brain capillary blood volume, [90] and progressive pneumatization of the facial bones [46] which collectively allow the head to remain balanced as facial tissues enlarge with growth. The physiologic result is a circular growth pattern around the basioccipital portion of the occipital condyles. The occipital condyles in norma lateralis have been observed slightly dorsal to the calculated center of mass for preserved head specimens, [91] however this is due to artifacts [90, 92]. MRI displays a $4 \%$ greater brain volume and weight resulting from the volume of blood in gray matter capillaries in the living brain, [90] which may cause the center of mass to be located directly over the occipital condyles. Maintenance of head balance is important as it seems that CFG emanates from the occipital condyles [93] which are along the central growth axis of the body and proximate the brainstem, around which the brain grows centripetally. Balance of the head would reduce any unnecessary metabolic demand required of the musculature for an upright posture; conservation of energy from an evolutionary standpoint.

The proposed CFG model is able to explain the developmental and functional observations of airorhynchy and the facial block hypothesis [12,31]. The concept of brain temporal lobe growth displacing the ACB forward must deal with the asymmetric growth of the SOS, lack of brain temporal lobe/middle cranial fossa elongation, [11] and lack of a direct articulation between the MCB and maxilla due to separation by the infraorbital fissure. Additionally, current consensus seems to be that the nasal septum functions to support the roof of the nasal chamber rather than actively participate in the displacement of the palate itself by approximately 4 years of age $[4,13,14,94]$. On the whole, the tissue(s) that displaces the maxilla downward with craniofacial growth postnatally have not yet been satisfactorily defined relative to the competing nasal septum theory and functional matrix theory [26].

\section{Airway and Speech Development Through CFMAS Tension}

Sagittal rotation of the cranium at the occipital condyles and asymmetric growth at the SOS are proposed to cause the face to rotate cephalad and ventral, opening the airway with normal jaw rotation and extension of tissues (lingual tonsil, velum) [95, 96] (Fig. 6). The resultant relative descent of the larynx develops the hyolaryngeal complex, [12] creating a resonance chamber to allow voice production for speech.

Transverse development of the maxilla and nasal airway is believed to be a result of muscle mass increases resulting in greater CFMAS tension which causes the teeth to be compressed (keeping in mind the relative separation of the jaws with growth). Developed is a greater posterior relative to anterior transverse increase of the maxilla and nasal airway with growth (molar force is greater due to the Class 3 lever system of the jaws) [27]. The functional occlusion of the teeth displaces the maxillary halves, thereby increasing the transverse airway and providing room for the tongue. The tongue has been believed to play a major role in transverse airway enlargement, however the apposition observed on the bony palate during growth [13,97] seems dismissive of a pressure large enough to displace the maxillary shelves. Also, the comparable posterior face height of individuals with hyperdivergent/leptoprosopic (simply, long faced) profiles to those with the hypodivergent/europrosopic (simply, short faced) profiles also raises questions of relative posterior tongue posture [98].

Lateral midfacial muscle attachments may also play a minor role in developing transverse nasal dimension. Craniofacial muscles are bilateral and, through lateral attachment relative to the midfacial bone centroids (center rotation), may cause lateral rotation below the centroid and medial rotation above the centroids. This may contribute to the inverted " $\mathrm{V}$ " shape [13] of the nasal aperture, in conjunction with occlusal forces transmitted across the palate and mid-palatal suture. This must be weighed against the reciprocal forces from the muscles of mastication.

\section{SUPPORT FOR THE PROPOSED MODEL}

\section{The Effect of Cranial Rotation in the Expression of Facial form}

Maxillomandibular rotation with craniofacial growth (CFG) had not been apparent until the Bjork implant studies of the mid-fifties [20]. Yet, as a whole, the interrelationship between the growth of the maxilla and mandible is still not fully understood, and remains one of the great challenges of craniofacial biologists [14]. 


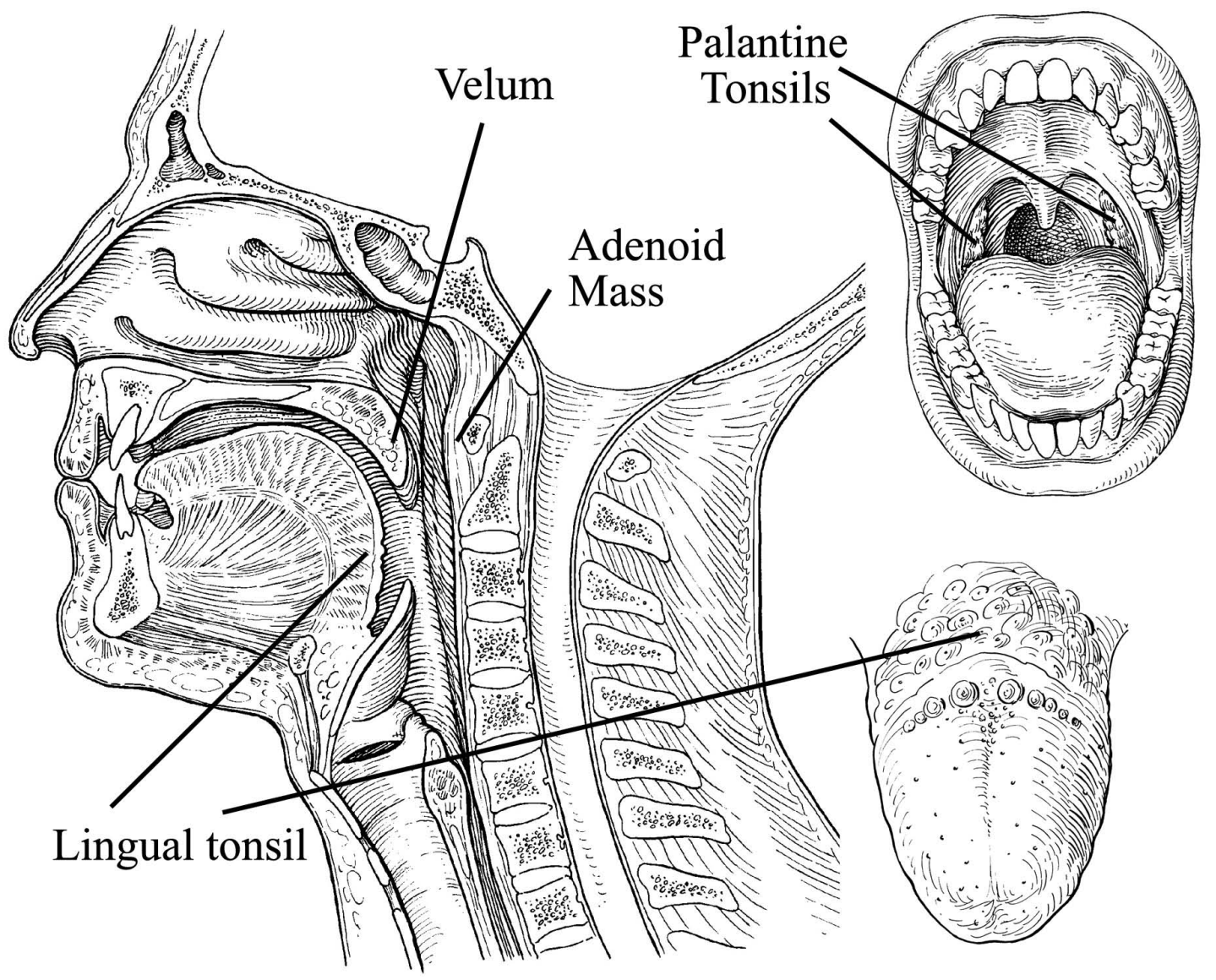

Fig. (6). Illustrated are the components of Waldeyer's ring of lymphoid tissue: the palatine tonsils, adenoid tissue mass and lingual tonsil. Enlargement of the nasal lining with rhinitis can alter laminar airflow. Normal mandibular rotation is expected to direct the tongue forward through muscle attachment at the genial tubercles (internal surface of the mandibular symphysis). Cranial rotation serves to direct the velum forward in coordination with differential SOS growth.

The CFMAS tension is not only a dorsal restrictive pressure as with the soft tissue stretching CFG model proposed by Solow, [17] but displays a relative cephalad tension capable of directing anabolic growth. The CFMAS tension is also opposite to the dorsal/caudad force expected from suprahyoid muscle attachment relative to cervical vertebrae growth of the Houston CFG model [16] (Fig. 1).

\section{Maxillomandibular Rotation and TMJ Modeling Result- ing from Differences in CFMAS Somatotype}

The inherent (genetic) contribution of the CFMAS in the brachycephalic and dolichocephalic individual is believed to influence maxillomandibular rotation [75, 99]. Brachycephalic individuals tend to be europrosopic, strong muscled [100] and display a hypodivergent radiographic profile, while dolichocephalic individuals tend to be leptoprosopic, weak muscled [100] and display a hyperdivergent radiographic profile (see Dale [101] for a detailed comparison).

In general, CFMAS tension is believed to be related to resting muscle tonus [61] and the connective tissue compliance, and is greater in the europrosopic versus leptoprosopic individual resulting from muscle morphology [100].

During normal CFG rotation, the tension through the CFMAS is expected to modify the effects of gravity on the viscerocranium as muscle growth increases with puberty, along with progressive densification and crosslinking of the associated connective tissue component (Fig. 5) until age related CFMAS tension attenuation occurs [54]. The effect of the CFMAS resisting gravity may result in the anterior displacement of the midface by maxillary contact with the mandible through a functional occlusion of the teeth. The divergence of the facial planes in combination with the opposing gravity and CFMAS forces seem to create a wedge effect (Fig. 3). Hence, leptoprosopic facial types which display a hyperdivergent mandibular plane angle usually display a sagittally retruded maxilla, as will be further explored.

\section{The Anatomic Perspective of the Proposed Mandibular Rotation Around the Pterygomasseteric Sling}

The rotation axis of the mandible has been postulated but not definitively ascertained. Therefore, based on current anatomical understanding, the pivot point for mandibular rotation is proposed at the pterygomasseteric sling $(\mathrm{PtmS})$ which is formed by the blended aponeuroses of the masseter and medial pterygoid muscles at the angle of the mandible [102, 103]. Horizontal motion of the mandible is allowed as the sling cradles the mandible, in addition to mandibular rotation around the "true" pterygomasseteric sling (PtmS). The PtmS is proposed as original neonatal muscle attachment site that 
approximates the neutral zone of the mandibular periosteal sleeve where little periosteal migration occurs [104] (Fig. 7). As children grow, there is a migration of the periosteum and associated muscle attachments; [105-107] muscle portions nearer this neutral zone would be expected to remain positionally stable and/or new muscle attachment/heads developed [103, 108] (Fig. 5).

\section{The Normal to Brachycephalic Individual (Forward/ Counter-Clockwise Rotation)}

In the mesocephalic to brachycephalic individual, tension in the CFMAS passes through the anterior of the mandible via the modiolus and osteocutaneous ligaments, (Figs. 1 and 3) and is believed to cause a forward/counter-clockwise (CCW) maxillomandibular rotation described by Bjork [20, 109].

The effect of gravity on the CFMAS suspended viscerocranial elements includes other elements resting on the skeletal units; for example, the eyeballs. The reason that the viscerocranial elements can be suspended relative to the cephalad force of the functional occlusion and not provide compression to the circumaxillary sutures may be in part that, unlike the rather direct distraction of the sutures resulting from the force of gravity, the force of the functional occlusion is redistributed throughout the skull due to buttressing [110] (Fig. 8) and compression of the bone. Due to proximity, orientation and the initial buttressing, the direct affect of functional occlusion on the palatal suture is not common to all the circumaxillary sutures.

$\mathrm{CCW}$ mandibular rotation causes distraction (separation) of the articular surfaces of the temporomandibular joint, resulting in bone apposition on the anterior surface of the con- dylar head (Fig. 7) and the articular eminence of the temporal bone [102]. This results in caudad movement of the gonial angle leading to increased ramal height relative to anterior face height, [102] a more caudally positioned glenoid fossa and steeper articular eminence [111]. CCW rotation of the mandible also results in increased overbite and progressive restriction of the mandibular dentoalveolar complex on the basal bone $\mathrm{e}^{36}$ and causes overjet to open and the incisors impinge on the tongue. The wedge cross-section shape of the teeth results in an increased overjet as the overbite increases, and the mandibular incisors tend to drift labially relative to implants due to the tongue impingement, as demonstrated by Bjork [21]. CCW rotation increases the space anterior to the ramus for tooth eruption relative to the position of the PtmS; therefore tooth crowding is less probable in these individuals.

\section{Dolichocephalic Individuals (Backward/Clockwise Man- dibular Rotation)}

Dolichocephalic individuals often display a decreased biting strength and backward/clockwise (CW) maxillomandibular rotation compared to mesocephalic individuals, which is believed to be a result of decreased CFMAS tension. Airway obstruction is often a concern with these individuals resulting in a neuromuscular response that positions the tongue relatively forward [101] of the PtmS causing the gravitational effects to overly dominate CFMAS effectsThis results in a more pronounced $\mathrm{CW}$ rotation of the mandible, a narrow and longer face, and posterior rotation in nose shape (dorsal hump). Condylar growth is restricted by compression at the articular surfaces of the mandibular condyle and articular eminence resulting in a glenoid fossa that is relatively more cephalad and shallow [111, 112]. The
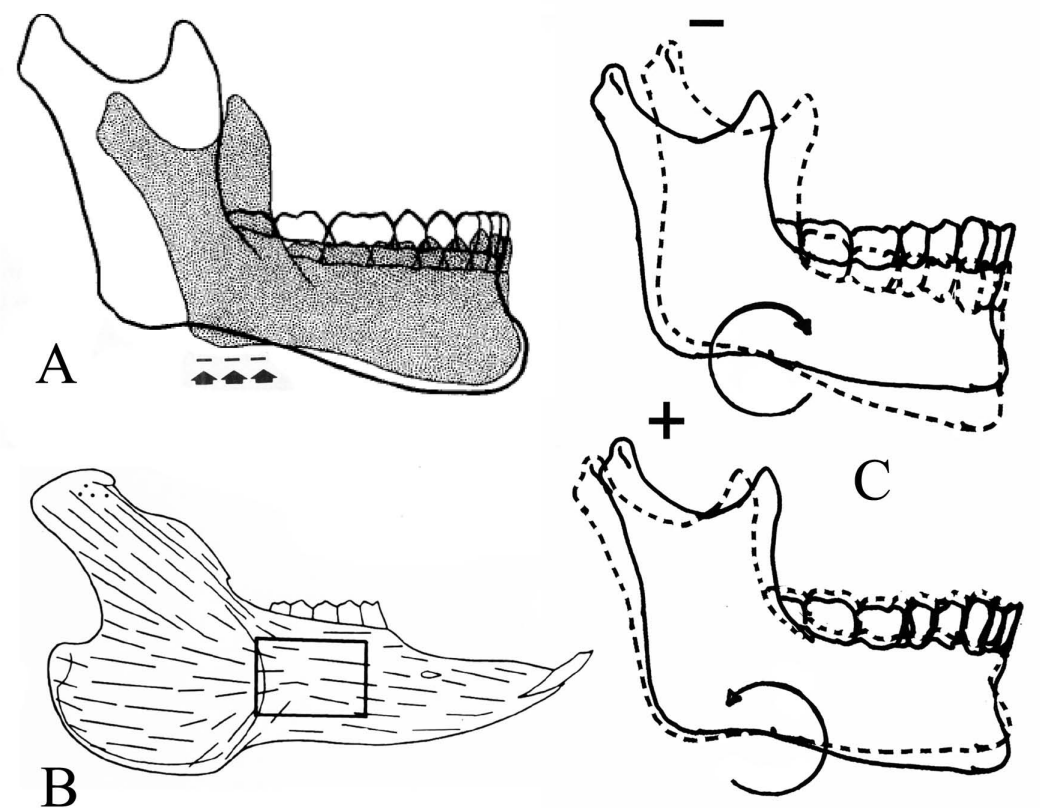

Fig. (7). (A) The site of the PtmS is shown with arrows, which corresponds to the original/neonate location of the pterygomasseteric sling. Illustration from [117] (B) Shown is the neutral zone observed in the periosteum of the rabbit mandible, which is an area of little expected muscle attachment migration. Illustration from [104] (C) CW and CCW rotation is illustrated; with backward (CW) rotation there is inhibition/resorption at the condyle and with forward (CCW) rotation there is distraction of the condyle articular surface and associated anabolic modeling; compensatory modeling at menton and gonion, and tooth eruption are not shown. 

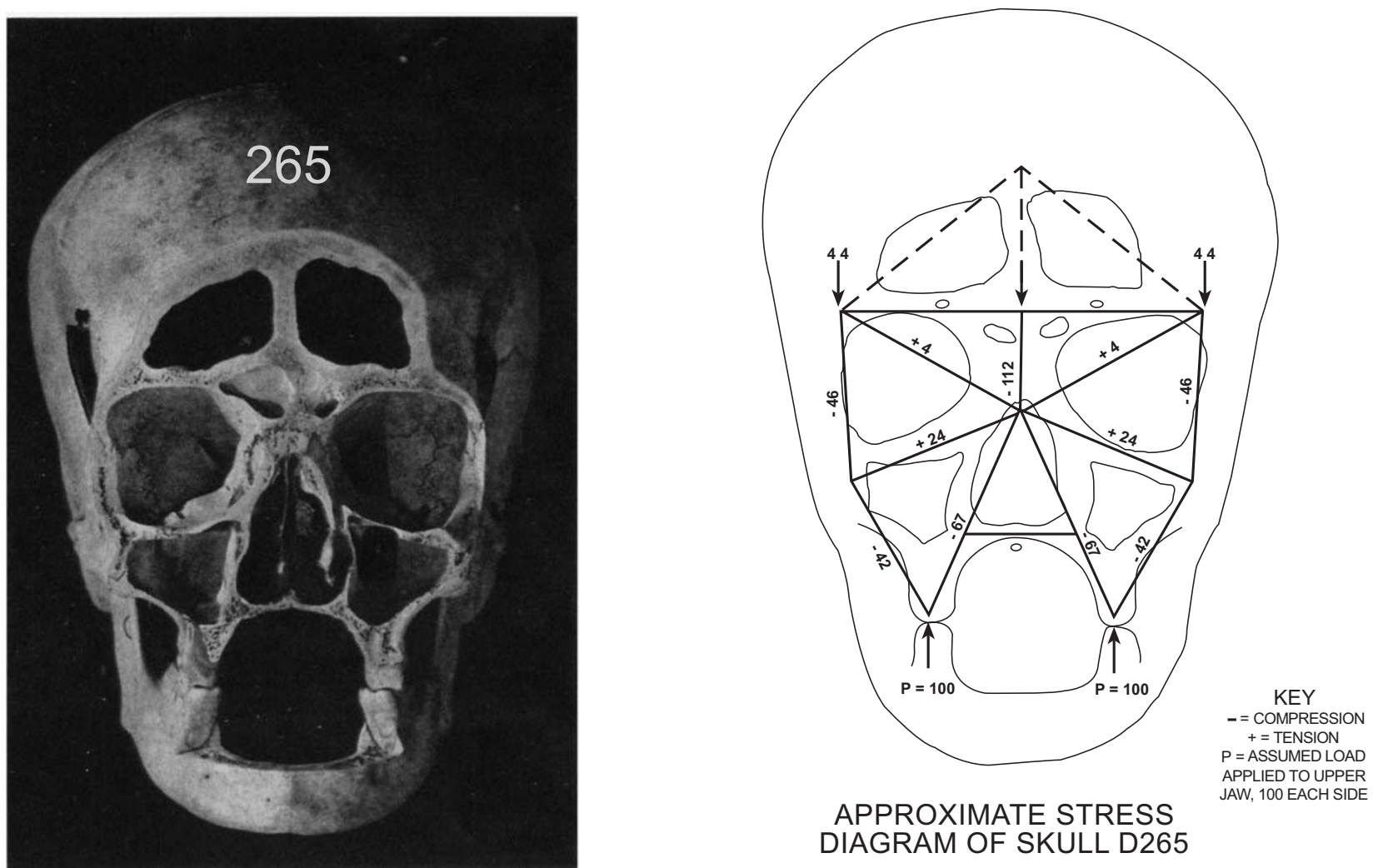

Fig. (8). The force vector resulting from the functional occlusion of teeth is not equal and opposite to the force vector of gravity; therefore, functional occlusion would not be expected to place circumaxillary sutures in compression. Figure from [110].

CFMAS causes superficial pressure induced resorption of the anterior maxilla, [27] maxillary retrusion, resorption at menton and the mandibular teeth are posteriorly inclined, as gravity's effect on the mandible is resisted by the CFMAS. This reduces the relative depth of B-point and anterior orientation of the symphysis. The mandible tends to grow ventral less than in the europrosopic individual and the caudad force on the anterior mandible predominates. The anterior mandible bends over the PtmS as a result of the forward tongue posture and restriction of the PtmS which accentuates the antegonial notch in combination with matrix apposition at gonion as a result of tissue stretch to the periosteum. The issue of Wolff's law must be analyzed in light of nontraditional microscopy patterns on the bony surfaces of necropsy specimens [113]. Since there is a CW rotation around the PtmS, (Fig. 7) the ramus does not move dorsal relative to the PtmS, resulting in an increase probability of tooth crowding.

\section{Experimental Observations in the Rat}

In rats, this muscle dependant mandibular rotation and associated articular cartilage change overlying the head of the mandibular condyle has been demonstrated by Navarro [102]. Increased thickness of the condylar cartilage, length of the ramus after temporalis muscle resection (TR) and opening of the Stutzmann's angle (estimates the direction of condylar growth) were described as unexpected; however, the observations fit well with the proposed model of rotation around the PtmS. With masseter muscle resection (MR), there was a backward rotation of the mandible and with TR, there was a forward rotation. Considering rotation of the mandible around the PtmS, MR releases the restrictive element of the PtmS, while TR releases tension posterior to the PtmS allowing forward rotation of the mandible. The authors [102] concluded that alterations in masticatory musculature can modify "articular growth". Observation of the mandibular condyle articular cartilage displayed an increase in thickness with TR and a decrease in thickness with MR. A thinner ramus was observed with $\mathrm{MR}$ and an increased ramus was noted with TR. These are expected with the proposed mechanism of craniofacial growth.

\section{CONCLUSIONS}

The ability to model growth patterns will lead to further understanding and insights. Cephalometric study based on the occipital condyles as the craniofacial growth axis leads to a more biologically correct craniofacial growth model. This aponeurotic tension model of craniofacial growth, in which brain growth and cranial rotation create cephalad tension within the inter-related superficial musculoaponeurotic systems of the head and face, adds clarity to the mechanism of maxillomandibular rotation and TMJ development. The modeling of craniofacial growth is important when considering surgical intervention during growth, prediction of condy- 
lar resorption, post-surgical relapse, temporomandibular joint dynamics/growth, understanding of airway, future beneficial surgical procedures and age specific plasticity of tissues.

\section{ACKNOWLEDGEMENT}

We would like to thank Professor Manuel Chanavaz, (Oral and Maxillofacial Implantology, Faculty of Medicine, University of Lille, France) for his guidance with muscle growth concepts.

\section{REFERENCES}

[1] Proffit WR, Fields HW. Contemporary orthodontics. 3rd ed. St. Louis: Mosby 2000.

[2] Roberts WE, Hartsfield JK, Jr. Bone development and function: Genetic and environmental mechanisms. Semin Orthod 2004; 10(2): 100-22.

[3] Moss ML. A theoretical analysis of the functional matrix. Acta Biotheor 1968; 18(1): 195-202.

[4] Carlson DS. Theories of craniofacial growth in the postgenomic era. Semin Orthod 2005; $11(4): 172-83$.

[5] Moss ML, Young RW. A functional approach to craniology. Am J Phys Anthropol 1960; 18: 281-92.

[6] Moss ML. Twenty years of functional cranial analysis. Am J Orthod 1972; 61(5): 479-85.

[7] Moss ML, Salentijn L. The primary role of functional matrices in facial growth. Am J Orthod 1969; 55(6): 566-77.

[8] Moss ML. In: Moyers RE, Krogman WM, Eds. Ontogenetic aspects of cranio-facial growth. $1^{\text {st }}$ ed. Oxford, New York: Pergamon Press 1971.

[9] Scott JH. The cartilage of the nasal septum: a contribution to the study of facial growth. Br Dent J 1953; 95: 37-43.

[10] Dixon A, Hoyte D, Rönning O. Fundamentals of craniofacial growth. Boca Raton: CRC Press 1997.

[11] Hoyte DA. The cranial base in normal and abnormal skull growth. Neurosurg Clin North Am 1991; 2(3): 515-37.

[12] Lieberman DE, Ross CF, Ravosa MJ. The primate cranial base: ontogeny, function, and integration. Am J Phys Anthropol 2000; Suppl 31: 117-69.

[13] Enlow DH, Hans MG. Essentials of facial growth. Philadelphia: Saunders 1996.

[14] Ranly DM. Craniofacial growth. Dent Clin North Am 2000; 44(3): 457-70.

[15] Latham RA, Scott JH. A newly postulated factor in the early growth of the human middle face and the theory of multiple assurance. Arch Oral Biol 1970; 15(11): 1097-100.

[16] Houston WJ. Mandibular growth rotations, their mechanisms and importance. Eur J Orthod 1988; 10(4): 369-73.

[17] Solow B, Kreiborg S. Soft-tissue stretching: a possible control factor in craniofacial morphogenesis. Scand J Dent Res 1977; 85(6): 505-7.

[18] Petrovic A. Control of postnatal growth of secondary cartilages of the mandible by mechanisms regulating occlusion. Cybernetic model. Trans Eur Orthod Soc 1974; 69-75.

[19] Petrovic A, Stutzmann J, Lavergne J. Mechanisms of craniofacial growth and modus operandi of functional appliances: a cell-level and cybernetic approach to orthodontic decision making. In: Carlson DS, Ed; Craniofacial growth theory and orthodontic treatment: Craniofacial growth series 23. Ann Arbor: Center for Human Growth \& Development, The University of Michigan 1990.

[20] Bjork A. Facial growth in man, studied with the aid of metallic implants. Acta Odontol Scand 1955; 13(1): 9-34.

[21] Bjork A, Skieller V. Normal and abnormal growth of the mandible: a synthesis of longitudinal cephalometric implant studies over a period of 25 years. Eur J Orthod 1983; 5(1): 1-46.

[22] Wang JC, Nuccion SL, Feighan JE, Cohen B, Dorey FJ, Scoles PV. Growth and development of the pediatric cervical spine documented radiographically. J Bone Joint Surg Am 2001; 83-A(8): 1212-8.

[23] Cohen MM, Jr. Sutural biology and the correlates of craniosynostosis. Am J Med Genet 1993; 47(5): 581-616.
[24] Wagemans PA, van de Velde JP, Kuijpers-Jagtman AM. Sutures and forces: a review. Am J Orthod Dentofacial Orthop 1988; 94(2): 129-41.

[25] Roberts W. Bone Physiology, metabolism, and biomechanics in orthodontic practice. In: Graber TM, Vanarsdall RL, Vig KWL, Eds. Orthodontics : Current principles \& techniques. 4 ed. St. Louis, Mo.: Elsevier Mosby 2005; pp. 221-92.

[26] Ranly DM. A synopsis of craniofacial growth. New York: Appleton-Century-Crofts 1980.

[27] Bjork A, Skieller V. Growth of the maxilla in three dimensions as revealed radiographically by the implant method. $\mathrm{Br} \mathrm{J}$ Orthod 1977; 4(2): 53-64.

[28] Bjork A, Skieller V. Facial development and tooth eruption. An implant study at the age of puberty. Am J Orthod 1972; 62(4): 33983 .

[29] Bjork A. Sutural growth of the upper face studied by the implant method. Acta Odontol Scand 2007; 29: i82-i8.

[30] Roberts WE, Roberts JA, Epker BN, Burr DB, Hartsfield Jr JK. Remodeling of mineralized tissues, Part I: the frost legacy. Semin Orthod 2006; 12(4): 216-37.

[31] McCarthy RC, Lieberman DE. Posterior maxillary (PM) plane and anterior cranial architecture in primates. Anat Rec 2001; 264(3): 247-60.

[32] Bjork A, Skieller V. Postnatal growth and development of the maxillary complex. In: Moyers RE, McNamara JA, Eds. Factors affecting the growth of the midface, proceedings of a sponsored symposium honoring Professor Robert E Moyers, held February 6 and 7, 1976, in Ann Arbor, Michigan. Ann Arbor: Craniofacial Publications, CHGD 1976; pp. 61-99.

[33] Giedd JN, Blumenthal J, Jeffries NO, et al. Brain development during childhood and adolescence: a longitudinal MRI study. Nat Neurosci 1999; 2(10): 861-3.

[34] Kushima H, Matsuo K, Yuzuriha S, Kitazawa T, Moriizumi T. The occipitofrontalis muscle is composed of two physiologically and anatomically different muscles separately affecting the positions of the eyebrow and hairline. Br J Plastic Surg 2005; 58: 681-7.

[35] Abramo AC. Anatomy of the forehead muscles: the basis for the videoendoscopic approach in forehead rhytidoplasty. Plast Reconstr Surg 1995; 95(7): 1170-7.

[36] Gola R. The forehead cutaneo-musculo-aponeurotic unit and aging of the forehead. Anatomo-physiological considerations and surgical implications. Ann Chir Plast Esthet 1999; 44(1): 89-102.

[37] Hwang K, Kim DJ, Hwang SH. Insertion of frontalis muscle relating to blepharoptosis repair. J Craniofac Surg 2005; 16(6): 965-7.

[38] Jacobs RM, Brodie AG. The analysis of perioral muscular accommodation in young subjects with malocclusion. Angle Orthod 1966; 36(4): 325-34

[39] Letourneau A, Daniel RK. The superficial musculoaponeurotic system of the nose. Plast Reconstr Surg 1988; 82(1): 48-57.

[40] Spiegel JH, DeRosa J. The anatomical relationship between the orbicularis oculi muscle and the levator labii superioris and zygomaticus muscle complexes. Plast Reconstr Surg 2005; 116(7): 1937-42; discussion 43-4.

[41] Bjork A. Cranial base development: : a follow-up x-ray study of the individual variation in growth occuring between the ages of 12 and 20 years and its relation to brain case and face development. Am J Orthod 1955; 41: 198-225.

[42] Bergersen EO. The directions of facial growth from infancy to adulthood. Angle Orthod 1966; 36(1): 18-43.

[43] Broadbent BH. The face of the normal child. Angle Orthod 1937; 7(4): 183-208.

[44] Coben SE. Growth concepts. Angle Orthod 1961;31(3): 194-201

[45] Melsen B. The cranial base : the postnatal development of the cranial base studied histologically on human autopsy material. Thesis. Acta Odontol Scand 1974; 32 (Suppl 62).

[46] Standerwick R, Roberts E, Hartsfield J Jr., Babler W, Kanomi R. Cephalometric superimposition on the occipital condyles as a longitudinal growth assessment reference: I-point and I-curve. Anat Rec (Hoboken) 2008; 291(12): 1603-10.

[47] Standerwick RG, Roberts WE, Hartsfield JK, Jr, Babler WJ, Katona TR. Comparison of the bolton standards to longitudinal cephalograms superimposed on the occipital condyle (I-point). J Orthod 2009; 36: 23-35.

[48] Enlow DH, Kuroda T, Lewis AB. The morphological and morphogenetic basis for craniofacial form and pattern. Angle Orthod 1971; 41(3): 161-88 
[49] Ghafari J, Engel FE, Laster LL. Cephalometric superimposition on the cranial base: a review and a comparison of four methods. Am J Orthod Dentofacial Orthop 1987; 91(5): 403-13.

[50] Bastir M, Rosas A. Correlated variation between the lateral basicranium and the face: a geometric morphometric study in different human groups. Arch Oral Biol 2006; 51(9): 814-24.

[51] Sahin B, Acer N, Sonmez OF, et al. Comparison of four methods for the estimation of intracranial volume: a gold standard study. Clin Anat 2007; 20(7): 766-73.

[52] Broadbent BH, Broadbent BH, Golden WH. Bolton standards of dentofacial developmental growth. Saint Louis: Mosby 1975.

[53] Friede H. Normal development and growth of the human neurocranium and cranial base. Scand J Plast Reconstr Surg 1981; 15(3): 163-9.

[54] Stuzin JM, Baker TJ, Gordon HL. The relationship of the superficial and deep facial fascias: relevance to rhytidectomy and aging. Plast Reconstr Surg 1992; 89(3): 441-9; discussion 50-1.

[55] Har-Shai Y, Bodner SR, Egozy-Golan D, et al. Mechanical properties and microstructure of the superficial musculoaponeurotic system. Plast Reconstr Surg 1996; 98(1): 59-70; discussion 1-3.

[56] Mitz V, Peyronie M. The superficial musculo-aponeurotic system (SMAS) in the parotid and cheek area. Plast Reconstr Surg 1976; 58(1): 80-8.

[57] Saulis AS, Lautenschlager EP, Mustoe TA. Biomechanical and viscoelastic properties of skin, SMAS, and composite flaps as they pertain to rhytidectomy. Plast Reconstr Surg 2002; 110(2): 590-8; discussion 9-600.

[58] Gans BJ, Sarnat BG. Sutural facial growth of the Macaca rhesus monkey: a gross and serial roentgenographic study by means of metallic implants. Am J Orthod 1951; 37(11): 827-41.

[59] Delaire J, Ed. The potential role of facial muscles in monitoring maxillary growth and morphogenesis. Ann Arbor: Craniofacial Publications, CHGD 1978.

[60] Delaire J. Maxillary development revisited: relevance to the orthopaedic treatment of Class III malocclusions. Eur J Orthod 1997; 19(3): 289-311.

[61] Palla S. The vertical dimension: a prosthodontist's perspective. In: McNamara J, Jr, Ed. The enigma of the vertical dimension: craniofacial growth series 36. Ann Arbor: Craniofacial Publications, CHGD 2000. pp. 75-101.

[62] Nishimura T, Ojima K, Liu A, Hattori A, Takahashi K. Structural changes in the intramuscular connective tissue during development of bovine semitendinosus muscle. Tissue Cell 1996; 28(5): 527-36.

[63] Ferrario VF, Dellavia C, Tartaglia GM, Turci M, Sforza C. Soft tissue facial morphology in obese adolescents: a three-dimensional noninvasive assessment. Angle Orthod 2004; 74(1): 37-42.

[64] Hunt N, Shah R, Sinanan A, Lewis M. Muscling in on malocclusions: current concepts on the role of muscles in the aetiology and treatment of malocclusion. Northcroft memorial lecture 2005. J Orthod 2006; 33(3): 187-97.

[65] Goldspink G. The proliferation of myofibrils during muscle fibre growth. J Cell Sci 1970; 6(2): 593-603.

[66] Pierson CR, Agrawal PB, Blasko J, Beggs AH. Myofiber size correlates with MTM1 mutation type and outcome in X-linked myotubular myopathy. Neuromuscul Disord 2007; 17(7): 562-8.

[67] Williams PE, Goldspink G. Longitudinal growth of striated muscle fibres. J Cell Sci 1971; 9(3): 751-67.

[68] Goldspink G. Changes in striated muscle fibres during contraction and growth with particular reference to myofibril splitting. J Cell Sci 1971; 9(1): 123-37.

[69] Goldspink G. Sarcomere length during post-natal growth of mammalian muscle fibres. J Cell Sci 1968; 3(4): 539-48.

[70] Woo SL, Debski RE, Zeminski J, Abramowitch SD, Saw SS, Fenwick JA. Injury and repair of ligaments and tendons. Annu Rev Biomed Eng 2000; 2: 83-118.

[71] Gao Y, Kostrominova TY, Faulkner JA, Wineman AS. Age-related changes in the mechanical properties of the epimysium in skeletal muscles of rats. J Biomech 2008; 41(2): 465-9.

[72] Nishimura T, Hattori A, Takahashi K. Structural changes in intramuscular connective tissue during the fattening of Japanese black cattle: effect of marbling on beef tenderization. J Anim Sci 1999; 77(1): 93-104.

[73] Alnaqeeb MA, Al Zaid NS, Goldspink G. Connective tissue changes and physical properties of developing and ageing skeletal muscle. J Anat 1984; 139 (Pt 4): 677-89.
[74] Millward DJ. Metabolic demands for amino acids and the human dietary requirement: Millward and Rivers (1988) revisited. J Nutr 1998; 128(12 Suppl): 2563S-76S.

[75] Lewis MP, Machell JR, Hunt NP, Sinanan AC, Tippett HL. The extracellular matrix of muscle-implications for manipulation of the craniofacial musculature. Eur J Oral Sci 2001; 109(4): 209-21.

[76] Martin RB, Burr DB, Sharkey NA. Skeletal tissue mechanics. New York: Springer 1998.

[77] Fang SH, Nishimura T, Takahashi K. Relationship between development of intramuscular connective tissue and toughness of pork during growth of pigs. J Anim Sci 1999; 77(1): 120-30.

[78] De Deyne PG, Meyer R, Paley D, Herzenberg JE. The adaptation of perimuscular connective tissue during distraction osteogenesis. Clin Orthop Relat Res 2000; 379: 259-69.

[79] Melsen B. The postnatal growth of the cranial base in Macaca rhesus analyzed by the implant method. Tandlaegebladet 1971; 75(12): 1320-9.

[80] Baume LJ. Principles of cephalofacial development revealed by experimental biology. Am J Orthodont 1961; 47(12): 881-901.

[81] Vilmann H, Kirkeby S, Moss ML. Studies on orthocephalization. IV. differential growth of the sphenooccipital synchondosis in the rat. Anat Anz 1980; 148(2): 97-104.

[82] Lei WY, Wong RWK, Rabie ABM. Factors regulating endochondral ossification in the spheno-occipital synchondrosis. Angle Orthod 2008; 78(2): 215-20.

[83] Kyrkanides S, Kambylafkas P, Miller JH, Tallents RH, Puzas JE. The cranial base in craniofacial development: a gene therapy study. J Dent Res 2007; 86(10): 956-61.

[84] Stokes IA, Aronsson DD, Dimock AN, Cortright V, Beck S. Endochondral growth in growth plates of three species at two anatomical locations modulated by mechanical compression and tension. J Orthop Res 2006; 24(6): 1327-34.

[85] Carter DR, Wong M. Modelling cartilage mechanobiology. Philos Trans R Soc Lond B Biol Sci 2003; 358(1437): 1461-71.

[86] Wang X, Mao JJ. Chondrocyte proliferation of the cranial base cartilage upon in vivo mechanical stresses. J Dent Res 2002; 10: 701-5.

[87] Thilander B, Ingervall B. The human spheno-occipital synchondrosis. II. a histological and microradiographic study of its growth. Acta Odontol Scand 1973; 31(5): 323-34.

[88] Babler WJ, Persing JA. Experimental alteration of cranial suture growth: effects on the neurocranium, basicranium, and midface. Prog Clin Biol Res 1982; 101: 333-45.

[89] Gogtay N, Giedd JN, Lusk L, et al. Dynamic mapping of human cortical development during childhood through early adulthood. Proc Natl Acad Sci USA 2004; 101(21): 8174-9.

[90] Courchesne E, Chisum HJ, Townsend J, et al. Normal brain development and aging: quantitative imaging at in vivo MR imaging in health volunteers. Radiology 2000; 216(3): 672-82.

[91] Vital JM, Senegas J. Anatomical bases of the study of the constraints to which the cervical spine is subject in the sagittal plane: a study of the center of gravity of the head. Surg Radiol Anat 1986; 8(3): 169-73.

[92] Quester R, Schroder R. The shrinkage of the human brain stem during formalin fixation and embedding in paraffin. J Neurosci Methods 1997; 75(1): 81-9.

[93] Frankel R. The applicability of the occipital reference base in cephalometrics. Am J Orthod 1980; 77(4): 379-95.

[94] Thilander B. Basic mechanisms in craniofacial growth. Acta Odontol Scand 1995; 53(3): 144-51.

[95] Moss ML, Rankow RM. The role of the functional matrix in mandibular growth. Angle Orthod 1968; 38(2): 95-103.

[96] Tourne LP. Growth of the pharynx and its physiologic implications. Am J Orthod Dentofacial Orthop 1991; 99(2): 129-39.

[97] Enlow DH, Bang S. Growth and remodeling of the human maxilla. Am J Orthod 1965; 51: 446-64.

[98] Nanda S. Patterns of vertical growth in the face. Am J Orthod Dentofacial Orthop 1988; 93(2): 103-16.

[99] Tippett HL, Dodgson LK, Hunt NP, Lewis MP. Indices of extracellular matrix turnover in human masseter muscles as markers of craniofacial form: a preliminary study. Eur J Orthod 2008; 30(2): 21725.

[100] Pepicelli A, Woods M, Briggs C. The mandibular muscles and their importance in orthodontics: a contemporary review. Am J Orthod Dentofacial Orthop 2005; 128(6): 774-80. 
[101] Dale JG, Dale HC, Eds. Interceptive guidance of occlusion with emphasis on diagnosis. 4th ed. St. Louis, Mo.: Elsevier Mosby 2005.

[102] Navarro M, Delgado E, Monje F. Changes in mandibular rotation after muscular resection: experimental study in rats. Am J Orthod Dentofacial Orthop 1995; 108(4): 367-79.

[103] El Haddioui A, Bravetti P, Gaudy JF. Anatomical study of the arrangement and attachments of the human medial pterygoid muscle. Surg Radiol Anat 2007; 29(2): 115-24.

[104] Frankenhuis-Van Den Heuvel TH, Maltha JC, Kuijpers-Jagtman AM, Van 't Hof MA. A longitudinal radiographic study of the periosteal migration along the growing rabbit mandible. J Dent Res 1992; 71(2): 398-402.

[105] Dorfl J. Migration of tendinous insertions. I: cause and mechanism. J Anat 1980; 131(Pt 1): 179-95.

[106] Grant PG, Buschang PH, Drolet DW, Pickerell C. Invariance of the relative positions of structures attached to long bones during growth: cross-sectional and longitudinal studies. Acta Anat (Basel) 1980; 107(1): 26-34.

[107] Covell DA, Jr, Herring SW. Periosteal migration in the growing mandible: an animal model. Am J Orthod Dentofacial Orthop 1995; 108(1): 22-9.

[108] Grant PG. The effect of position on the migration of muscle. J Anat 1978; 127(Pt 1): 157-62.
[109] Bjork A. Prediction of mandibular growth rotation. Am J Orthod 1969; 55(6): 585-99.

[110] Atkinson S. Balance- the magic word. Am J Orthod 1964; 50(3): 189-202.

[111] Baccetti T, Antonini A, Franchi L, Tonti M, Tollaro I. Glenoid fossa position in different facial types: a cephalometric study. $\mathrm{Br} \mathrm{J}$ Orthod 1997; 24(1): 55-9.

[112] Schellhas KP, Wilkes CH, Fritts HM, Omlie MR, Lagrotteria LB. MR of osteochondritis dissecans and avascular necrosis of the mandibular condyle. AJR Am J Roentgenol 1989; 152(3): 551-60.

[113] Hans MG, Enlow DH, Noachtar R. Age-related differences in mandibular ramus growth: a histologic study. Angle Orthod 1995; 65(5): 335-40.

[114] Solow B, Tallgren A. Dentoalveolar morphology in relation to craniocervical posture. Angle Orthod 1977; 47(3): 157-64.

[115] Liebgott B. The anatomical basis of dentistry. Rev Rep ed. St. Louis: C.V. Mosby 1986.

[116] Rubin LR. Reanimation of the paralyzed face: new approaches. St Louis: C.V. Mosby 1977.

[117] Enlow DH. Wolff's law and the factor of architectonic circumstance. Am J Orthod 1968; 54(11): 803-22. 